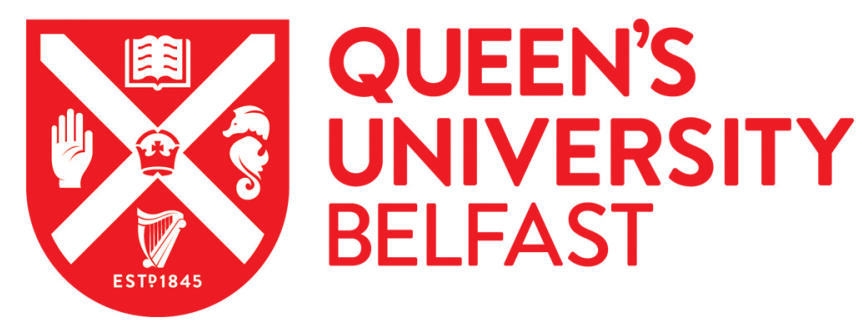

\title{
Pulpotomy for mature carious teeth with symptoms of irreversible pulpitis: A systematic review
}

Cushley, S., Duncan, H. F., Lappin, M., Tomson, P. L., Lundy, F. T., Cooper, P., Clarke, M., \& El Karim, I. A. (2019). Pulpotomy for mature carious teeth with symptoms of irreversible pulpitis: A systematic review. Journal of Dentistry, 88, [103158]. https://doi.org/10.1016/j.jdent.2019.06.005

Published in:

Journal of Dentistry

Document Version:

Peer reviewed version

Queen's University Belfast - Research Portal:

Link to publication record in Queen's University Belfast Research Portal

\section{Publisher rights}

Copyright 2019 Elsevier.

This manuscript is distributed under a Creative Commons Attribution-NonCommercial-NoDerivs License

(https://creativecommons.org/licenses/by-nc-nd/4.0/), which permits distribution and reproduction for non-commercial purposes, provided the author and source are cited.

\section{General rights}

Copyright for the publications made accessible via the Queen's University Belfast Research Portal is retained by the author(s) and / or other copyright owners and it is a condition of accessing these publications that users recognise and abide by the legal requirements associated with these rights.

Take down policy

The Research Portal is Queen's institutional repository that provides access to Queen's research output. Every effort has been made to ensure that content in the Research Portal does not infringe any person's rights, or applicable UK laws. If you discover content in the Research Portal that you believe breaches copyright or violates any law, please contact openaccess@qub.ac.uk. 


\section{Accepted Manuscript}

Title: Pulpotomy for mature carious teeth with symptoms of irreversible pulpitis: A systematic review

Authors: Siobhan Cushley, Henry F. Duncan, Mark Lappin, Phillip L Tomson, Fionnuala T Lundy, Paul Cooper, Mike Clarke, Ikhlas A. El Karim

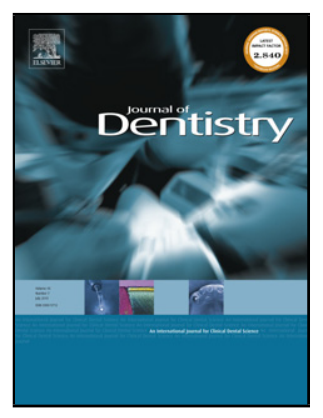

PII:

DOI: S0300-5712(19)30129-0

Reference: https://doi.org/10.1016/j.jdent.2019.06.005

To appear in: JJOD 3158

Received date: Journal of Dentistry

Revised date:

7 March 2019

Accepted date:

24 May 2019

20 June 2019

Please cite this article as: Cushley S, Duncan HF, Lappin M, Tomson PL, Lundy FT, Cooper P, Clarke M, El Karim IA, Pulpotomy for mature carious teeth with symptoms of irreversible pulpitis: A systematic review, Journal of Dentistry (2019), https://doi.org/10.1016/j.jdent.2019.06.005

This is a PDF file of an unedited manuscript that has been accepted for publication. As a service to our customers we are providing this early version of the manuscript. The manuscript will undergo copyediting, typesetting, and review of the resulting proof before it is published in its final form. Please note that during the production process errors may be discovered which could affect the content, and all legal disclaimers that apply to the journal pertain. 
Pulpotomy for mature carious teeth with symptoms of irreversible pulpitis: A systematic review

Running title: Pulpotomy for irreversible pulpitis

\section{Authors}

Siobhan Cushley

Centre for Dentistry, School of Medicine Dentistry and Biomedical Sciences, Queen's University Belfast, Belfast, UK

Henry F. Duncan

Division of Restorative Dentistry \& Periodontology, Dublin Dental University Hospital, Trinity College Dublin, University of Dublin, Lincoln Place, Dublin, Ireland.

Mark Lappin

Centre for Dentistry, School of Medicine Dentistry and Biomedical Sciences, Queen's University Belfast, Belfast,

Phillip L Tomson

The University of Birmingham School of Dentistry, Institute of Clinical Sciences, 5 Mill Pool Way, Edgbaston, Birmingham, UK

Fionnuala T Lundy

The Wellcome-Wolfson Institute for Experimental Medicine, School of Medicine, Dentistry and Biomedical Sciences, Queen's University Belfast, 97 Lisburn Road, Belfast, UK 
Oral Biology, The University of Birmingham School of Dentistry, Institute of Clinical Sciences, 5 Mill Pool Way, Edgbaston, Birmingham, U`K

Mike Clarke

Centre for Public Health, School of Medicine, Dentistry and Biomedical Sciences, Queen's University Belfast, Institute of Clinical Sciences Block B, Belfast UK

Ikhlas A. El Karim

The Wellcome-Wolfson Institute for Experimental Medicine, School of Medicine, Dentistry and Biomedical Sciences, Queen's University Belfast, 97 Lisburn Road, Belfast, UK

\section{Corresponding Author's address}

Dr Ikhlas A. El Karim

The Wellcome-Wolfson Institute for Experimental Medicine, School of Medicine, Dentistry and Biomedical Sciences, Queen's University Belfast, 97 Lisburn Road, Belfast, BT9 7BL, United Kingdom

Email: i.elkarim@qub.ac.uk

Tel: +442890976026

\section{ABSTRACT}




\section{Objectives}

Management of carious teeth with signs and symptoms indicative of irreversible pulpitis is traditionally invasive, but emerging evidence suggests successful treatment outcomes with less invasive vital pulp treatment such as coronal pulpotomy.

The objective of this systematic review is to determine whether coronal pulpotomy is clinically effective in treating carious teeth with signs and symptoms indicative of irreversible pulpitis.

\section{Sources}

MEDLINE; PubMed; Embase, Web of Science, Cochrane Central Register of Controlled Trials, International Clinical Trials Registry Platform and ClinicalTrials.gov were searched until December 2018.

\section{Study selection}

Prospective, retrospective and randomised clinical trials investigating coronal pulpotomy or comparing pulpotomy to root canal treatment in permanent mature carious teeth with signs and symptoms indicative of irreversible pulpitis were included. Studies were independently assessed for risk of bias using Cochrane Systematic Reviews of intervention criteria and modified Downs and Black quality assessment checklist.

\section{Data}

Eight articles were selected for analysis. The average success rate for coronal pulpotomy was $97.4 \%$ clinical and $95.4 \%$ radiographic at 12 month follow-up. This 
was reduced to $93.97 \%$ clinical and $88.39 \%$ radiographic success at 36 months follow-up. Results from the only comparative clinical trial showed pulpotomy to have comparable success to root canal treatment at 12, 24 and 60 month follow-up.

\section{Conclusions}

The evidence suggests high success for pulpotomy for teeth with signs and symptoms of irreversible pulpitis, however, results are based on heterogeneous studies with high risk of bias. Well-designed, adequately powered randomised controlled trials are required for evidence to change clinical practice.

Clinical significance: Management of carious teeth with irreversible pulpitis is traditionally invasive, but emerging evidence suggests potentially successful treatment outcomes with less invasive therapies such as coronal pulpotomy

Key words: Irreversible pulpitis, pulpotomy, root canal treatment, caries 


\section{INTRODUCTION}

Dental caries in permanent teeth represents the most prevalent disease worldwide [1]. Untreated caries can progress to induce severe inflammation in the dental pulp, resulting in pain, pulp necrosis and abscess formation. The dental pulp responds to caries by a complex inflammatory response that is currently described in a simple dichotomous way as reversible or irreversible pulpitis. According to the American Association of Endodontists' (AAE 2013) [2] classification, reversible pulpitis is a clinical diagnosis based upon subjective and objective findings indicating that the inflammation should resolve following appropriate management of the aetiology. Irreversible pulpitis on the other hand, indicates an inflamed pulp that is incapable of healing and for which root canal treatment is indicated. Such a diagnosis is, however, based on crude diagnostic tools that do not accurately represent the true pathological state of the pulp [3]. Histological and microbiological studies have shown that the inflammation and microbial presence in teeth traditionally diagnosed with irreversible pulp disease is limited to the coronal pulp tissue and that there is an absence of bacterial invasion and inflammation in the radicular pulp [4]. These findings have led to challenges of the established classifications and the introduction of new diagnostic terms and management strategies [5]. Critically, it has been proposed that pulpectomy may not be necessary after caries exposure in cases with signs or symptoms indicative of irreversible pulpitis [5]; however, it should be noted that at present these new management strategies are not supported by robust randomised clinical trials.

Irreversible pulpitis is traditionally treated with pulpectomy and root canal treatment. This treatment is generally successful if well carried out $[6,7]$, but it is destructive, 
expensive, technically challenging and time-consuming. Removal of the pulp tissue can also structurally weaken the tooth, rendering it more susceptible to fracture, further infection and caries [8]. These issues highlight the importance of maintaining pulpal vitality to the health of the tooth and demonstrate the clinical need to develop biologically-based minimally invasive solutions in restorative dentistry $[5,9,10]$.

Pulpotomy is a minimally invasive procedure whereby the inflamed/diseased pulp tissue is removed from the coronal pulp chamber of the tooth leaving healthy pulp tissue which is dressed with a dental biomaterial that maintains pulpal vitality and promotes repair [11]. The procedure can either be partial (whereby $2-3 \mathrm{~mm}$ of the coronal pulp is removed) or complete pulpotomy (in which the entire coronal pulp is removed). In mature permanent teeth, coronal pulpotomy has been successfully reported as an emergency pain relief procedure prior to root canal treatment [12]. However, with the development of bioactive materials and improved biocompatibility $[13,14]$, pulpotomy has been reinvestigated as a definitive treatment of permanent teeth with pulpitis [15]. A systematic review on the outcome of total coronal pulpotomy, showed an overall favourable outcome of the procedure [16]. In Alqaderi's review, the majority of included studies have a diagnosis of reversible pulpitis or there was a history of no spontaneous pain indicating such a diagnosis. There is no systematic review data focussing only on the outcome of pulpotomy for teeth with signs and symptoms indicative of irreversible pulpitis. Recently, several small studies have proposed that cariously exposed teeth with signs and symptoms of irreversible pulpitis can be successfully managed with pulpotomy procedures [1721]. A non-inferiority randomised clinical trial comparing root canal treatment to pulpotomy concluded that pulpotomy was actually superior to root canal treatment in mature permanent molar teeth with irreversible pulpitis [22,23]. In view of increasing 
interest in minimally invasive dentistry and the challenge to existing diagnosis and treatment of irreversible pulpitis [5], it is appropriate to evaluate and critically appraise the emerging literature and to synthesize evidence to inform clinical decision making. Unlike previously published reports, this systematic review is based on data solely relating to the diagnosis of irreversible pulpitis as defined in the AAE classification [2].

\section{Objectives}

The main objective of this review is to determine the success rate of complete coronal pulpotomy in carious teeth with signs and symptoms indicative of irreversible pulpitis. A subsidiary aim is to evaluate whether pulpotomy is as successful as root canal treatment in carious teeth with signs and symptoms indicative of irreversible pulpitis.

\section{MATERIALS AND METHODS}

This systematic review is reported using the PRISMA guidelines and the PICO framework to address the following clinical questions: "What is the success rate of full coronal pulpotomy in treating carious mature permanent teeth with signs and symptoms indicative of irreversible pulpitis and what is the success rate of coronal pulpotomy compared with the success rate of root canal treatment in such teeth?". Where $(P=$ population $)$ is the carious teeth with signs and symptoms indicative of irreversible pulpitis; $(\mathrm{I}=$ Intervention) is coronal pulpotomy; $(\mathrm{O}=$ outcome $)$ is clinical effectiveness and ( $\mathrm{C}=$ comparison) is root canal treatment. 


\subsection{Information sources and search strategy}

Electronic searches: Electronic database searches were undertaken using a combination of key search words (pulpotomy, pulpitis, caries, success rate, root canal treatment $[\mathrm{RCT}]$ and permanent teeth). These MeSH search items and search strategy (Supplementary Table 1) were developed for our MEDLINE search and adopted for other electronic databases. The following databases were searched, with the most recent search being carried out in December 2018 with no language restriction:

- MEDLINE, 1960 to present, in-process and other non-indexed citations, Ovid SP

- Cochrane Central Register of Controlled Trials (CENTRAL), International Clinical Trials Registry Platform (ICTRP) and ClinicalTrials.gov

- Embase, 1960 to present, Ovid SP

- Web of Science

Searching other resources: To ensure literature saturation, reference lists of included studies and reviews were checked for eligible studies. Open SIGLE database was also searched for grey literature, to identify studies not indexed in the databases listed above.

\subsection{Study selection process}

Studies were eligible for the review if they satisfied the following inclusion criteria: 
- Type of studies: Prospective, retrospective and randomised control clinical trials involving human subjects and carried out in either hospital or primary care settings.

- Type of participants: Patient with permanent mature carious teeth with signs and symptoms indicative of irreversible pulpitis.

- Complete coronal pulpotomy carried out on carious permanent mature teeth with vital pulp and diagnosis of irreversible pulpitis and in comparative studies, root canal treatment as control.

- Type of outcome: Long-term success of pulpotomy which is defined as; (1) radiographic success in which there was no abnormality suggestive of apical periodontitis as well as resolution (decrease in size or elimination) of an existing radiographic periapical lesion, and (2) clinical success where there were no clinical symptoms of spontaneous pain, tenderness to percussion and/or no swelling or sinus tract [24]. Long-term success is also defined by minimum 12 month follow-up period.

Secondary outcomes related to the question of effectiveness, such as patient and operator satisfaction; economic evaluations and quality of life measures were considered if reported in the included studies.

Studies were excluded if they:

- Investigated deciduous and solely immature permanent teeth or pulp exposure caused by trauma

- Were case reports, expert opinions or reviews.

- Assessed other procedures, including apexogenesis, direct or indirect pulp capping. 
- Did not specify, or separate teeth based on, whether the pulpitis was reversible or irreversible.

The PRISMA flow chart (Figure. 1) illustrates the selection process. For screening and assessment of eligibility criteria, titles and abstracts were screened by three assessors independently (SC, IEK, HD). Full text was obtained for all studies that met the inclusion criteria or when the abstract did not contain enough information to make a decision on the selection criteria. Disagreement was resolved by discussion. Full text articles were assessed for quality and inclusion in possible meta-analysis by three assessors independently (SC, IEK, ML).

\subsection{Quality assessment of included studies}

Three assessors (SC, IEK, ML) independently assessed risk of bias for each included study. The methodological quality of non-randomised studies was assessed using modified Downs and Black quality assessment checklist [25] and domains covered for this scale included; reporting, external and internal validity (bias and confounding) and power. Each domain is assigned a score and the total score for each study is provided. Randomised controlled trials risk of bias was assessed using the criteria outlined in the Cochrane Handbook for Systematic Reviews of Interventions [26]. A high or low risk of bias was assigned to an individual study, when there was evidence or absence of the following variables; selection bias, detailed allocation information, performance bias, detection details, attrition details, selective reporting bias or "other bias" that did not fall into any of the listed categories. Unclear risk of bias was assigned when there was insufficient information to permit judgment of low risk or high risk. 
Furthermore, the evidence level for each of the included studies was graded using the Oxford Centre for Evidence-Based Medicine recommendation (http://www.cebm.net/oxford-centre-evidence-based-medicine-levels-evidencemarch-2009/)[27].

\subsection{Data collection/extraction process}

Data were extracted by two authors independently (SC, IEK) using custom designed data extraction forms (adopted form the Cochrane library). Extracted data included; type of study, number and demographics of participants, diagnosis, intervention, capping material, follow up period, number lost to follow-up, funding source, location of the study and final outcomes. The final data to be included were agreed by three authors (SC, IEK, ML) and any differences of opinion were resolved by further discussion and, if necessary, arbitration by a fourth person (HD). In studies reporting mixed data (e.g. reversible and irreversible pulpitis), whenever possible, only data that were relevant to the inclusion criteria were extracted and if it was not possible to disaggregate data in this way, the study was excluded. The extracted data were checked for accuracy by two authors (IEK, HD).

\subsection{Data synthesis}

Data entry and synthesis was carried out on Review Manager, Version 5.3. (The Nordic Cochrane Centre, the Cochrane Collaboration, Copenhagen, Denmark). Heterogeneity was assessed by calculating $I^{2}$ statistic and defined in accordance with the Cochrane Handbook as $\mathrm{I}^{2}<30 \%$ : acceptable heterogeneity, $\mathrm{I}^{2}$ of $30-60 \%$ : 
moderate heterogeneity, $I^{2}>60 \%$ : substantial heterogeneity [26]. Meta-analysis will be performed if heterogeneity is acceptable or moderate. The success rate whether clinical or radiographic for pulpotomy or root canal treatment, was calculated for each study by dividing the number of successful cases by the total number of cases.

\section{RESULTS}

\subsection{Selected studies}

Details of the study selection process are outlined in Figure 1. Thirty-seven, full text articles were excluded and the reasons explained (Table 1). Eight articles met the inclusion criteria for the review and these were; five articles reporting five different studies [17-21], and three articles reporting different time point data for one randomised control trial $[22,23,29]$. The details of included studies were outlined in Table 2 and those of the study populations in Table 3.

\subsection{Quality assessment of included studies}

The quality assessment of non-randomised studies showed all assessed studies had fair quality as determined using modified Downs and Black checklist (Supplementary Table 2). Risk of bias assessment of the randomised control trial showed evidence of high risk of bias, particularly on blinding of operators (performance bias) and outcome assessors (detection bias). In the "other bias" item, unclear risk of bias was assigned as there was insufficient information to assess whether other risks of bias existed (e.g. bias towards specific study design or capping material used). (Supplementary Table 3). 


\subsection{Overall coronal pulpotomy success rate}

All of the included studies reported separate clinical and radiographic outcomes as indicators of success or failure of coronal pulpotomy except Linsuwanont and coworkers [20], who reported combined clinical and radiographic success. Individually, studies reported high success rate for pulpotomy at 12 and 36 month follow- up. However, different study designs and evident heterogeneity meant that the usual full meta-analysis was not advisable in this case. Instead, clinical and radiographic success rates on the data extracted were calculated from individual studies and provided simple averages for the studies with either 12 or 36 month follow-up. This showed high success rate at 12 months which tended to lower at 36 months (Table 4 and 5).

\subsection{Coronal pulpotomy versus root canal treatment}

The second aim of this review was to evaluate whether coronal pulpotomy is as clinically effective as root canal treatment using outcomes described above in the method section. Initial search identified two randomised control trials that compared pulpotomy and root canal treatment [22, 23, 28, 29]. The pulpal diagnosis in Galani et al. [28] is not consistent with diagnosis of irreversible pulpitis and therefore excluded. Asgary et al. 2013, 2014, 2015 [22, 23, 29] are reports on the only randomised controlled trial that compared pulpotomy with root canal treatment for teeth with irreversible pulpitis and provided long term follow-up data evaluating periapical health clinically and radiographically at 12,24 and 60 months. Their results showed high clinical success rate for both pulpotomy and root canal treatment at 12 month follow-up (97.6\%). The radiographic success for pulpotomy 
was also comparable to root canal treatment (92.2\% \& 89\% respectively) at 12 months. However, at 24 months the radiographic success rate is reduced for the two interventions (86.7 and $79.5 \%$ ), but the clinical success rate remains high at $98.1 \%$. At 60 months follow-up, the success reduced further and was $71.3 \%$ for pulpotomy and $65.8 \%$ for root canal treatment [29]. These studies however, showed evidence of high and unclear risk of bias, both as detection and performance bias (Supplementary Table 3).

Due to inadequate reporting in the included studies, it was not possible to perform analyses for the secondary outcomes (such as quality of life or cost effectiveness).

\section{DISCUSSION}

Previous systematic reviews focussing on the outcome of coronal pulpotomy $[30,16]$ analysed teeth with deep caries, but were not specifically limited to include only teeth with symptoms of irreversible pulpitis. This systematic review is the first to be limited to teeth with signs and symptoms indicative of irreversible pulpitis. We ensured that studies in which the diagnosis was not clearly detailed in the methods or where the results were contaminated with mixed diagnoses of reversible/irreversible pulpitis, were excluded. The review was also limited to studies that included mature carious teeth as the differing effect of pulpotomy on immature teeth and indeed traumatic exposures is well documented [31]. The well-defined inclusion and exclusion criteria facilitated a focussed literature search and inclusion of only studies that are relevant to the research question. 
The findings of the review showed an overall encouraging outcome for pulpotomy in teeth with signs and symptoms indicative of irreversible pulpitis, which is comparable to that of teeth with reversible pulpitis [16]. The included studies varied in design, number of participants and materials used for pulp capping, but all included patients with signs and symptoms of irreversible pulpitis. Accurate diagnosis of pulpal condition is problematic and based on unreliable methods [3,32], therefore care was taken to ensure that included studies satisfied the criteria for clinical diagnosis of irreversible pulpitis [2]. Another issue was the heterogeneity in reporting outcomes, with some studies reporting clinical and radiographic success, whilst others reported overall combined success or clinical success alone. At the outset it was agreed, that reporting of both the clinical and radiographic features were important indicators of periapical health and thus these were chosen as outcomes for both pulpotomy and root canal treatment [11]. Although some studies [21], reported on other outcomes such as mineralised barrier formation and canal obliterations, these were not included as outcome measures in this review because they can be difficult to visualise radiographically and may only be of histological relevance [33]. The formation of a hard tissue barrier is traditionally considered as a successful outcome measure in vital pulp treatment; but its presence does not guarantee vitality in pulpotomised teeth [34]. Therefore, as used in this review and also described by Zanini et al. [24], periapical health was considered a better and clinically relevant outcome to be considered for assessing success of pulpotomy procedures. Determination of periapical health is best achieved by radiographic examination, as assessment of vitality is problematic in pulpotomised teeth and therefore the use of high quality radiographs is essential for detection of early periapical changes. In this regard, Cone Beam Computerised Tomography (CBCT) may prove useful. However, 
all included studies reported radiographic changes with conventional radiographs and no study using CBCT was identified.

A reliable comparison of the outcomes of coronal pulpotomy and root canal treatment requires well-designed adequately powered randomised controlled trials but only one study (three articles) was found that satisfied the inclusion criteria and compared pulpotomy with root canal treatment. The study was a randomised clinical trial with evidence of high risk of bias. Nevertheless, the results support other studies that reported high success rate for pulpotomy.

The high success rate for pulpotomy at both 12 and 36 month follow-up is encouraging and could have implications for clinical practice. Coronal pulpotomy is less invasive and a technically simpler procedure than pulpectomy and could save time and effort for both patient and practitioner. The procedure could potentially be an alternative in situations where provision of root canal treatment is compromised by time, the scope of operator's practice and financial constraints. However, one additional conclusion from this systematic review is that there is a need for high quality studies comparing pulpotomy to root canal treatment, not only on clinical effectiveness but also including cost-effectiveness and quality of life.

Caution should be taken in generalising the findings of this review. The included studies vary in design, participant numbers and they are not at a low risk of bias. The risk of bias in the included studies was reported using standard and validated risk of bias assessment tools that include blinding as an important factor. The nature of interventions would make it difficult if not impossible to completely blind the operator (performance bias) or the assessor (detection bias) particularly with radiographic assessment of pulpotomy and root canal treatment. 
Although the studies included participants with a wide range of ages and had long follow-up periods, they were mostly done in hospital and university settings and are difficult to apply to primary care settings like General Dental Practice. There is an urgent need for pragmatic studies addressing these uncertainties in primary care. Another issue is the use of different capping materials used in different studies, e.g. Calcium silicate cement Biodentine, mineral trioxide aggregate (MTA) and the calcium-enriched-mixture cement. As noted above, different designs precluded use of further quantitative analysis to determine the effect of the material on the success rate. However, the materials used in all of the above studies were hydraulic calcium silicate cements [35] and many reports have previously suggested their superiority to calcium hydroxide as pulpotomy agents [36].

Despite the limitations highlighted above, this review has many elements of strength. The review has a focussed clinical question and used strict inclusion criteria to ensure the findings from this review can be applicable to cases of irreversible pulpitis. The study selection and evaluation process was also performed according to standard protocols. Although it was not possible to perform meta-analysis, success rate of pulpotomy for only irreversible pulpitis cases was calculated in studies that used mixed diagnoses. Both these aspects of the review strengthen the findings but may also have underestimated the success of the pulpotomy procedure.

\section{CONCLUSIONS}

Within the limitations of this review, the high success rate reported for pulpotomy suggests that this procedure offers hope as an alternative to root canal treatment in teeth with a diagnosis of irreversible pulpitis. However, well-designed and adequately 
powered randomised controlled trials are required to produce the evidence that would be needed to change clinical practice in this area.

\section{Declaration of interests}

$\bigotimes$ The authors declare that they have no known competing financial interests or personal relationships that could have appeared to influence the work reported in this paper.

$\square$ The authors declare the following financial interests/personal relationships which may be considered as potential $g$ interests:

\section{References}

[1] N.J. Kassebaum, E. Bernabé, M. Dahiya, B. Bhandari, C.J. Murray, W. Marcenes, Global burden of untreated caries: A systematic review and metaregression, J Dent. Res. 94 (2015) 650-58.

[2] Endodontic Diagnosis: American Association of Endodontists https://www.aae.org/specialty/wpcontent/.../sites/.../endodonticdiagnosisfall2013. pdf 2013 (accessed 12 June 2018).

[3] I.A. Mejàre, S. Axelsson, T. Davidson, F. Frisk, M. Hakeberg, T. Kvist et al., Diagnosis of the condition of the dental pulp: A systematic review, Int .Endodont J. 45 (2012) 597-13.

[4] D. Ricucci, S. Loghin, J.F. Siqueira, Correlation between clinical and histologic pulp diagnoses, J. Endododontics 40 (2014) 1932-39 
[5] W.J. Wolters, H.F. Duncan, P.L. Tomson, I.E. Karim, G. McKenna, M. Dorri, et al., Minimally invasive endodontics: a new diagnostic system for assessing pulpitis and subsequent treatment needs, Int. Endodontic J. 50 (2017) 825-29.

[6] Y.L. Ng, V. Mann, S. Rahbaran, J. Lewsey, K. Gulabivala, Outcome of primary root canal treatment: systematic review of the literature-Part 2. Influence of clinical factors, Int. Endodontic J. 41 (2008) 6-31.

[7] Y.L. Ng, V. Mann, S. Rahbaran, J. Lewsey, K. Gulabivala, Outcome of primary root canal treatment: systematic review of the literature-part 1. Effects of study characteristics on probability of success, Int. Endodontic J. 40 (2007) 921-939.

[8] D.J. Caplan, J. Cai, G. Yin, B.A. White, Root canal filled versus non-root canal filled teeth: a retrospective comparison of survival times, J Public. Health. Dent. 65 (2005) 90-96

[9] P.R. Cooper, M.J. Holder, A.J. Smith, Inflammation and regeneration in the dentin-pulp complex: a double-edged sword, J. Endododontics 40(2014) S46-51.

[10] H.F. Duncan, K.M. Galler, P.L Tomson, S. Simon, I. El-Karim, R.Kundzina, et al., European Society of Endodontology position statement: Management of deep caries and the exposed pulp, Int. Endodontic J. 2019 Jan 21. doi: 10.1111/iej.

[11] Quality guidelines for endodontic treatment: consensus report of the European Society of Endodontology European Society of Endodontology, Int. Endododontic J. 39(2006) 921-30.

[12] G. Hasselgren, C.Reit, Emergency pulpotomy: pain relieving effect with and without the use of sedative dressings, J. Endododontics 15(1989) 254-6.

[13] P.N. Nair, H.F. Duncan, T.R. Pitt Ford, H.U. Luder, Histological, ultrastructural and quantitative investigations on the response of healthy human pulps to experimental capping with mineral trioxide aggregate: a randomized controlled trial, Int. Endodontic J. 41 (2008) 128-150.

[14] P.L. Tomson, L.M. Grover, P.J. Lumley, A.J. Sloan, A.J. Smith, P.R. Cooper, Dissolution of bio-active dentine matrix components by mineral trioxide aggregate, J. Dent. 35 (2007) 636-642.

[15] S. Simon, M. Perard, M. Zanini, A.J. Smith, E. Charpentier, S.X. Djole, et al., Should pulp chamber pulpotomy be seen as a permanent treatment? Some preliminary thoughts, Int. Endodontic J. 46 (2013) 79-87

[16] H. Alqaderi, C.T. Lee, S. Borzangy, T.C. Pagonis, Coronal pulpotomy for cariously exposed permanent posterior teeth with closed apices: A systematic review and meta-analysis, J. Dent. 44(2016) 1-7.

[17] N.A. Taha, M.B. Ahmad, A. Ghanim, Assessment of Mineral Trioxide 
Aggregate pulpotomy in mature permanent teeth with carious exposures, Int. Endodontic J. 50 (2017)117-25

[18] N.A. Taha, S.Z. Abdulkhader, Outcome of full pulpotomy using Biodentine in adult patients with symptoms indicative of irreversible pulpitis, Int. Endodontic $\mathrm{J}$ $.51(2018) 819-28$

[19] N.A. Taha, S.Z. Abdulkhader, Full Pulpotomy with Biodentine in Symptomatic Young Permanent Teeth with Carious Exposure, J. Endodontics 44 (2018) 932937.

[20] P. Linsuwanont, K. Wimonsutthikul, U. Pothimoke, B. Santiwong, Treatment Outcomes of Mineral Trioxide Aggregate Pulpotomy in Vital Permanent Teeth with Carious Pulp Exposure: The Retrospective Study, J. Endodontics 43 (2017) 225-230.

[21] M.A. Qudeimat, A. Alyahya, A.A. Hasan, K.M. Barrieshi-Nusair, Mineral trioxide aggregate pulpotomy for permanent molars with clinical signs indicative of irreversible pulpitis: a preliminary study, Int. Endodontic J. 50(2017) 126-34.

[22] S. Asgary, M.J. Eghbal, J. Ghoddusi, Two-year results of vital pulp therapy in permanent molars with irreversible pulpitis: an ongoing multicenter randomized clinical trial, Clin. Oral Investig. 18 (2014) 635-641.

[23] S. Asgary, M.J. Eghbal, J. Ghoddusi, S. Yazdani, One-year results of vital pulp therapy in permanent molars with irreversible pulpitis: an ongoing multicenter, randomized, non-inferiority clinical trial, Clin. Oral. Investig. 17 (2013) 431-9

[24] M. Zanini, M. Hennequin, P.Y. Cousson, A review of criteria for the evaluation of pulpotomy outcomes in mature permanent teeth, J. Endodontics 42 (2016). 1167-74

[25] SH. Downs, N. Black, The feasibility of creating a checklist for the assessment of the methodological quality both of randomised and non-randomised studies of health care interventions. J Epidemiol Community Health 52 (1998) 377-84.

[26] J.P.T. Higgins, S. Green, Cochrane Handbook for Systematic Reviews of Interventions, version 5.1.2, Cochrane Collaboration, Oxford (UK), 2011.

[27] Medicine. OCfE-b. Levels of Evidence; [accessed 2018, September] Oxford (UK): Oxford Centre for Evidence-Based Medicine; 2009 [cited 2018, September]. Available from: http://www.cebm.net/oxford-centre-evidence-basedmedicine-levels-evidence-march-2009/.

[28] M. Galani, S. Tewari, P. Sangwan, S. Mittal, K V. umar, J. Duhan, Comparative Evaluation of Postoperative Pain and Success Rate after Pulpotomy and Root Canal Treatment in Cariously Exposed Mature Permanent Molars: A Randomized Controlled Trial, J. Endododontics 43(2017) 1953-62.

[29] S. Asgary, M.J. Eghbal, M. Fazlyab, A.A. Baghban, J. Ghoddusi, Five-year 
results of vital pulp therapy in permanent molars with irreversible pulpitis: a noninferiority multicenter randomized clinical trial, Clin. Oral. Investig 19 (2015) 33541.

[30] P. Aguilar, P. Linsuwanont, Vital pulp therapy in vital permanent teeth with cariously exposed pulp: a systematic review, J. Endododontics 37 (2011) 581587.

[31] D.E. Witherspoon, Vital pulp therapy with new materials: new directions and treatment perspectives-permanent teeth, J. Endododontics 34 (2008) S25-8.

[32] L.G. Levin, A.S Law, G.R. Holland, P.V. Abbott, R.S. Roda, Identify and define all diagnostic terms for pulpal health and disease states, $\mathrm{J}$. Endododontics 35 (2009) 1645-57.

[33] H. Fransson, E. Wolf, K. Petersson, Formation of a hard tissue barrier after experimental pulp capping or partial pulpotomy in humans: an updated systematic review, Int. Endododontic J. 49 (2016) 533-42

[34] A. Santini, Long-term clinical assessment of pulpotomies with calcium hydroxide containing ledermix in human permanent premolars and molars, Acta. Odontol .Pediatr. 7(1986) 45-50

[35] B.W. Darvell, R.C. Wu, MTA"-an Hydraulic Silicate Cement: review update and setting reaction, Dent. Mater. 27(2011) 407-22.

[36] Z. Li, L. Cao, M. Fan, Q. Xu, Direct Pulp Capping with Calcium Hydroxide or Mineral Trioxide Aggregate: A Meta-analysis, J. Endododontics 41(2015)141217. 


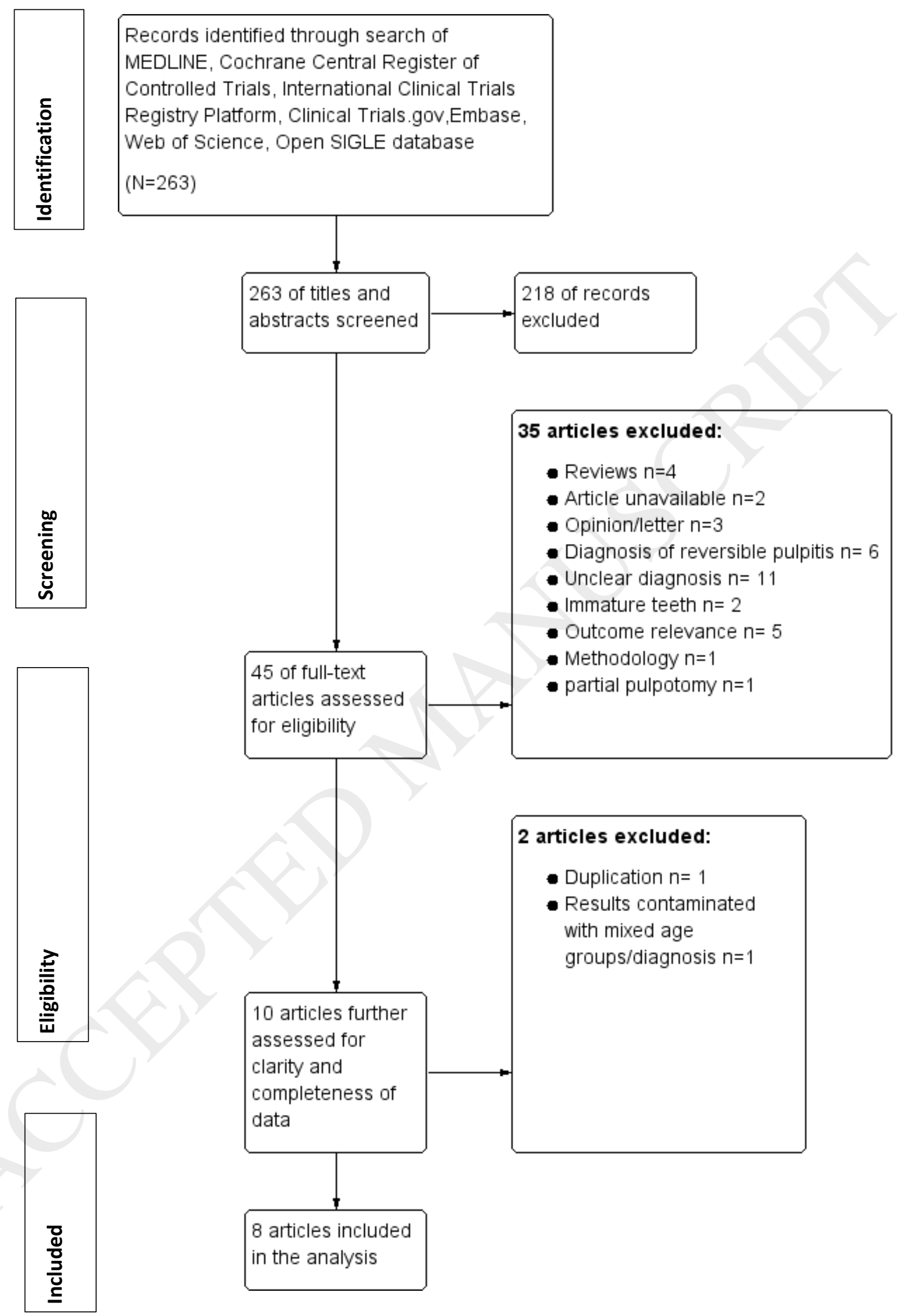

Figure1. PRISMA Flow Diagram illustrating articles selection process 


\section{Supporting information}

The supplementary data to this manuscript includes: Table I: search methods, Table

2: quality assessment of non-randomised studies, Table 3: quality assessment of the randomised clinical trials 
Table 1 Characteristics of excluded articles

\begin{tabular}{|c|c|c|}
\hline Reason for exclusion & Number of articles & Authors \\
\hline Review articles & 4 & $\begin{array}{l}\text { Brignardello-Petersen et al. } \\
2018 \\
\text { Brignardello-Petersen et al. } \\
2017 \\
\text { Asgary et al. } 2016 \\
\text { Britton } 1976\end{array}$ \\
\hline Article unavailable & 2 & $\begin{array}{l}\text { Dong et al. } 2017 \\
\text { Akbar et al. } 1987\end{array}$ \\
\hline $\begin{array}{l}\text { Opinion piece, letter or case } \\
\text { reports }\end{array}$ & 3 & $\begin{array}{l}\text { Zafar et al. } 2017 \\
\text { Fiskio } 1974 \\
\text { Malgaard } 1973\end{array}$ \\
\hline $\begin{array}{l}\text { Diagnosis of reversible } \\
\text { pulpitis }\end{array}$ & 6 & $\begin{array}{l}\text { Awawdeh et al } 2018 \\
\text { Chailertvanitkul et al. } 2014 \\
\text { Alqaderi et al. } 2014 \\
\text { Simon et al. } 2013 \\
\text { Barngkgei et al. } 2013 \\
\text { Barrieshi-Nusair et al. } 2006\end{array}$ \\
\hline $\begin{array}{l}\text { Pulpal diagnosis and or } \\
\text { status of the dental pulp not } \\
\text { provided }\end{array}$ & 11 & $\begin{array}{l}\text { Galani et al. } 2017 \\
\text { Cousson et al. } 2014 \\
\text { Bjørndal et al. } 2010 \\
\text { De Rosa et al. } 2006 \\
\text { De Marco et al. } 2005 \\
\text { Nosrat et al. } 1998 \\
\text { Caliskan et al. } 1995 \\
\text { Mass et al. } 1993 \\
\text { Caliskan et al. } 1993\end{array}$ \\
\hline
\end{tabular}




\begin{tabular}{|c|c|c|}
\hline & & $\begin{array}{l}\text { Santini } 1980 \\
\text { Frankl } 1978\end{array}$ \\
\hline Immature teeth & 2 & $\begin{array}{l}\text { Mejare et al. } 1993 \\
\text { Zilberman at al. } 1989\end{array}$ \\
\hline $\begin{array}{l}\text { Outcome irrelevant } \\
\text { /inconsistent with SR criteria }\end{array}$ & 5 & $\begin{array}{l}\text { Kumar et al. } 2016 \\
\text { Eghbal et al. } 2006 \\
\text { Hossseini } 1992 \\
\text { Santini } 1986 \\
\text { Barker } 1976\end{array}$ \\
\hline Methodology & 1 & Schwartz 1980 \\
\hline Duplicated studies & 1 & Asgary et al. 2017 \\
\hline $\begin{array}{l}\text { Data clarity preventing } \\
\text { extraction, including mixed } \\
\text { age participants, diagnosis } \\
\text { description or combination }\end{array}$ & 1 & Kunert et al. 2015 \\
\hline Partial pulpotomy & 1 & Taha \& Khazali, 2017 \\
\hline
\end{tabular}




\begin{tabular}{|c|c|c|c|c|c|c|c|}
\hline Author, year & Study design & Location & $\begin{array}{l}\text { Mean follow up } \\
\text { (month) }\end{array}$ & Intervention & Comparator & Outcome $^{*}$ Funding ${ }^{* *}$ & Level of Evidence ${ }^{\star \star *}$ \\
\hline $\begin{array}{l}\text { Taha } \\
\text { \&Abdulkhader,2018 } \\
{[18]}\end{array}$ & $\begin{array}{l}\text { Prospective } \\
\text { single arm }\end{array}$ & Jordan & 12 & $\mathrm{CP}$ & NA & $\begin{array}{l}\text { Clinical JUST } \\
\text { Radiographic }\end{array}$ & $2 b$ \\
\hline $\begin{array}{l}\text { Taha } \\
\text { \&Abdullkhader,2018 } \\
\text { [19] }\end{array}$ & $\begin{array}{l}\text { Prospective } \\
\text { single arm }\end{array}$ & Jordan & 12 & $\mathrm{CP}$ & NA & $\begin{array}{l}\text { Clinical JUST } \\
\text { Radiographic }\end{array}$ & $2 b$ \\
\hline $\begin{array}{l}\text { Qudeimat et al. } 2017 \\
\text { [21] }\end{array}$ & $\begin{array}{l}\text { Prospective } \\
\text { single arm }\end{array}$ & Kuwait & 52 & $\mathrm{CP}$ & NA & $\begin{array}{l}\text { Clinical NS } \\
\text { Radiographic }\end{array}$ & $2 b$ \\
\hline $\begin{array}{l}\text { Taha et al } 2017 \\
\text { [17] }\end{array}$ & $\begin{array}{l}\text { Prospective } \\
\text { single arm }\end{array}$ & Jordan & $12 \& 36$ & $\mathrm{CP}$ & NA & $\begin{array}{l}\text { Clinical JUST } \\
\text { Radiographic }\end{array}$ & $2 b$ \\
\hline $\begin{array}{l}\text { Linsuwanont et al } \\
2017 \text { [20] }\end{array}$ & Retrospective & Thailand & 36 & $\mathrm{CP}$ & NA & $\begin{array}{l}\text { Clinical NS } \\
\text { Radiographic }\end{array}$ & $2 b$ \\
\hline $\begin{array}{l}\phi \text { Asgary et al } 2013 \\
{[23]}\end{array}$ & $\begin{array}{l}\text { RCT parallel } \\
\text { arms comparing } \\
\text { RCT and } \\
\text { pulpotomy }\end{array}$ & Iran & 12 & $\mathrm{CP}$ & RCT & $\begin{array}{l}\text { Clinical } \\
\text { Radiographic }\end{array}$ & $1 b$ \\
\hline
\end{tabular}




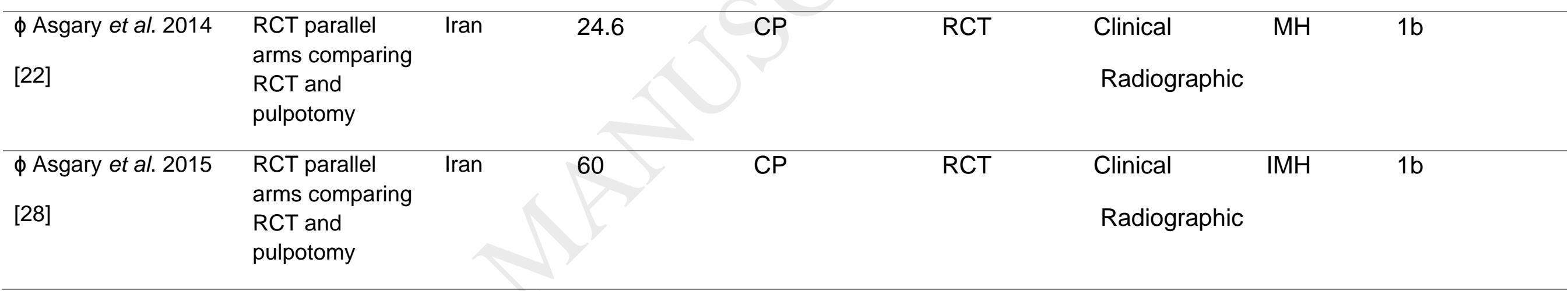

\section{Table 2: Included studies characteristics}

CP (Coronal pulpotomy)

* Clinical outcomes included history of spontaneous pain, swelling/abscess/sinus

${ }^{*}$ Radiographic outcomes: periapical changes indicative of apical periodontitis

** JUST (Jordan University of Science and Technology), IMH (Iran Ministry of Health), NS (source not specified)

${ }^{* * *}$ Oxford Centre for Evidence-Based Medicine; 2009

$\phi$ Same study but outcome assessed at different time point 
Table 3: Population characteristics

\begin{tabular}{|c|c|c|c|c|c|c|c|c|c|}
\hline Author, year & $\begin{array}{l}\text { Number } \\
\text { receiving } \\
\text { intervention }\end{array}$ & $\begin{array}{l}\text { Mean age } \\
\text { (years) }\end{array}$ & $\begin{array}{l}\text { Mean } \\
\text { follow up } \\
\text { (month) }\end{array}$ & $\begin{array}{l}\text { Tooth } \\
\text { Type }\end{array}$ & $\begin{array}{l}\text { Gender } \\
\text { M: F }\end{array}$ & Pulp Status & $\begin{array}{c}\text { PAP } \\
\text { Baseline }\end{array}$ & $\begin{array}{l}\text { Capping } \\
\text { Material }\end{array}$ & $\begin{array}{l}\text { Loss to } \\
\text { Follow-up }\end{array}$ \\
\hline
\end{tabular}

\section{Taha}

64

33.2

12

Molars

$31: 33$

IRP

9

Biodentine

4

[18]

Taha

\&Abdullkhader,2018

20

12

Molars

$10: 10$

IRP

7

Biodentine 0

[19]

Qudeimat et al. 2017

24

10.7

52

Molars

$12: 11 \neq$

IRP

7

MTA

1

[21]

Taha et al 2017 52

$11-51$

$12 \& 36$

Molars

$17: 26$

RP 8

14

MTA

12 at 12 month

[17]

Linsuwanont et al

66

29

36

NS

NS

IRP 44

11 at 36 month
RP 30

21

MTA 10

IRP 25 


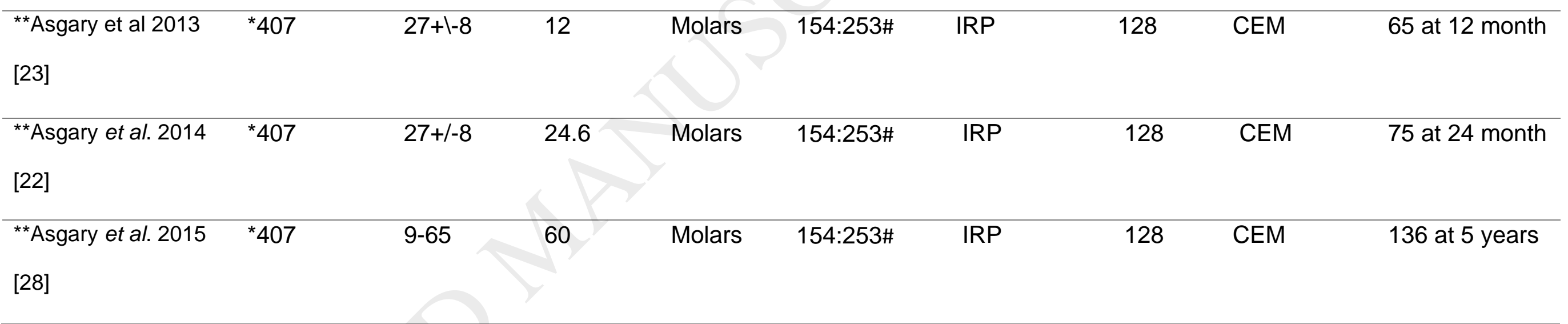

IRP (Irreversible pulpitis) RP (Reversible pulpitis) PAP (perapical periodontitis), NS (not specified)

MTA (mineral trioxide aggregate), CEM (calcium enriched mixture)

$\neq$ Gender of one participant lost to follow up not identified

* Total 407 teeth, 205 received pulpotomy and 202 received RCT

** Same study but outcome assessment at different time point

\# Figures obtained from cross reference of an earlier point publication of the trial findings 
Table 4: 12 month success of coronal pulpotomy in teeth with symptoms of irreversible pulpitis

\begin{tabular}{|c|c|c|c|c|c|}
\hline Author, year & $\begin{array}{l}\text { \#Number } \\
\text { receiving } \\
\text { intervention }\end{array}$ & $\begin{array}{l}\text { Observation } \\
\text { period } \\
\text { (months) }\end{array}$ & $\begin{array}{l}\text { Number at } \\
\text { follow-up }\end{array}$ & $\begin{array}{l}\text { Calculated\% } \\
\text { clinical } \\
\text { success }\end{array}$ & $\begin{array}{l}\text { Calculated \% } \\
\text { radiographic } \\
\text { success }\end{array}$ \\
\hline $\begin{array}{l}\text { Asgary et al. } \\
\text { 2013. [23] }\end{array}$ & 205 & 12 & 167 & 97.6 & 92.2 \\
\hline $\begin{array}{l}\text { Taha et al. } 2017 . \\
\text { [17] }\end{array}$ & $44^{*}$ & 12 & 32 & 100 & 96.8 \\
\hline $\begin{array}{l}\text { Taha \& } \\
\text { Abdulkhader } \\
\text { 2018. [19] }\end{array}$ & $17^{\star *}$ & 12 & 17 & 100 & 94.11 \\
\hline $\begin{array}{l}\text { Taha \& } \\
\text { Abdulkhader }\end{array}$ & 64 & 12 & 59 & 100 & 98.4 \\
\hline
\end{tabular}


Table 4: Success of pulpotomy in teeth with signs and symptoms indicative of irreversible pulpitis: the above numbers represent data extracted from included studies. Only data from subjects who met the review inclusion criteria was included in the analysis. Clinical and radiographic success rates were calculated by dividing the number of successful cases by the number at follow up.

\#Total numbers of participants who received the intervention and satisfied the review inclusion criteria

*Number of teeth with diagnosis of irreversible pulpitis from original 52 teeth receiving the intervention- 8 teeth with a diagnosis of reversible pulpitis were excluded and this together with attrition results in 32 patients for analysis.

** The number of teeth with mature roots and diagnosis of irreversible pulpitis from original 20 receiving intervention. 
Table 5: 36 month success of coronal pulpotomy in teeth with symptoms of irreversible pulpitis

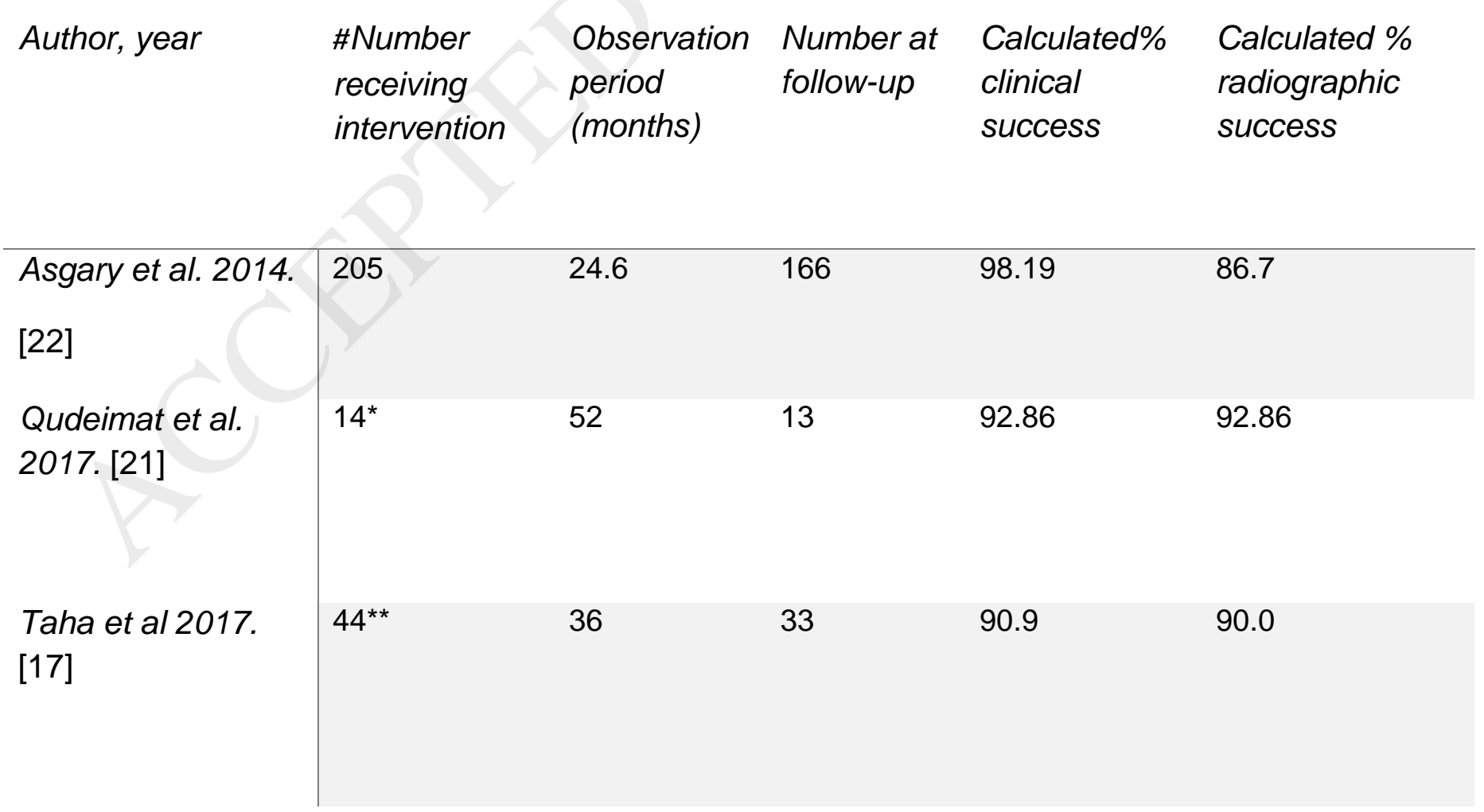


Linsuwanont et al 2017. [20]

Total/mean
$25^{* * *}$

36

37
25

233
84

88.39

Table 5: Success of pulpotomy in teeth with signs and symptoms indicative of irreversible pulpitis: the above numbers represent data extracted from included studies. Only data from subjects who met the review inclusion criteria was included in the analysis. Clinical and radiographic

success rates were calculated as shown in table 3.

\#Total numbers of participants who received the intervention and satisfied the review inclusion criteria

*The number of teeth with mature roots and diagnosis with irreversible pulpitis from original 24 receiving intervention with one tooth missing to follow up.

${ }^{* \star N}$ Number of teeth with diagnosis of Irreversible pulpitis from original 52 teeth receiving the intervention, 8 teeth with reversible pulpitis were excluded and this together with attrition result in 33 patients for analysis

${ }^{* *}$ Number of teeth with diagnosis of irreversible pulpitis from original 55 teeth included in the study. It is not clear how many of the 10 teeth with immature root apices had a diagnosis of irreversible pulpitis but the demographic of all failed cases were adults. 